\title{
THERMAL PROPERTIES OF Acacia mangium CROSS LAMINATED TIMBER AND ITS GLUELINES BONNDED WITH TWO STRUCTURAL ADHESIVES
}

\author{
Norwahyuni Mohd Yusof', \\ https://orcid.org/0000-0003-2549-437X \\ Paridah Md Tahir ${ }^{1, \$}$, \\ https://orcid.org/0000-0002-2961-6031 \\ Lee Seng $\mathrm{Hua}^{1, *}$, \\ https://orcid.org/0000-0001-6369-9902 \\ Fatimah Athiyah Sabaruddin, \\ https://orcid.org/0000-0001-8513-7441 \\ Redzuan Mohammad Suffian James, \\ https://orcid.org/0000-0001-8915-437X \\ Mohd Asim Khan', \\ https://orcid.org/0000-0001-9947-8730 \\ Lee Ching Hao ${ }^{\text {, }}$ \\ https://orcid.org/0000-0001-6347-9571 \\ Adlin Sabrina Muhammad Roseley ${ }^{2}$ \\ https://orcid.org/0000-0002-2616-3452
}

\begin{abstract}
The properties of cross laminated timber (CLT) can be affected by the type of adhesives used. The thermal properties of the adhesive that join the timber together is essential to determine the thermal endurance of the CLT product. In this study, two types of adhesives were used to join the cross laminated timber manufactured from Acacia mangium namely phenol resorcinol formaldehyde (PRF) and one component polyurethane (PUR). The thermal properties of the adhesives, A. mangium wood and the glue lines were determined via Thermogravimetric Analysis (TGA) and Dynamic Mechanical Analysis (DMA) tests. The TGA test showed that PRF adhesive had higher degradation temperature at $530{ }^{\circ} \mathrm{C}$ compared to PUR adhesive at $430{ }^{\circ} \mathrm{C}$. Meanwhile, the PRF adhesive as a glue line in CLT also showed better thermal resistance where a higher amount of residue of $20,94 \%$ was recorded at temperature up to $900{ }^{\circ} \mathrm{C}$ compared to PUR glue line with $18,26 \%$ residue. The integrity of the CLT over temperature was determined via DMA test and the results showed that PRF adhesive as glue line had superior properties, indicating better interfacial bonding with the woods.
\end{abstract}

Keywords: Acacia mangium, cross laminated timber, dynamic mechanical analysis, interfacial bonding, one component polyurethane, phenol resorcinol formaldehyde. 


\section{INTRODUCTION}

Cross-laminated timber (CLT) is a wood panel composite that joining at least three layers of solid-sawn timber by using an adhesive (Sutton et al. 2011). This material has been considered as high demand products that used as a constructional material for buildings. It enables a rapid installation for wall and floor structures that suitable for most finishes (Van De Kuilen et al. 2011). According to Dieste et al. (2019), CLT is a high value-added product compared to that of the other wood products. The mass production of CLT is formed in a similar way to "glue-laminated timber" beams using permanent adhesives which the limitations such as knots, checks, splits, warping and weathering can be removed to reduce variability and enhanced its structural properties. Almost all the studies of CLTs reported are constructed from softwood species such as spruce, larch, white fir, silver fir, Douglas fir, pine, and yellow poplar with density ranging from $350 \mathrm{~kg} / \mathrm{m}^{3}$ to $700 \mathrm{~kg} /$ $\mathrm{m}^{3}$ (Engineering Toolbox 2004). For instance, Wang et al. (2018) fabricated CLT from spruce-pine-fir lumber pieces to study the effects of edge-gluing and gap size in the cross layers.

The rapid industrialization and increasing number of populations in the world causes the depleting of forest wealth at a rapid rate. The issue has urged the manufacturers to make use of fast grown plantation species for various timber applications (Shukla 2019). To relieve the pressure of the continuous extraction of logs from local natural forest, the establishment of plantation forests is a matter of utmost urgency. In 2005, a Forest Plantation Programme has been implemented by the Ministry of Plantation Industries and Commodities (MPIC) where a total of 375000 ha of forest plantation has been targeted to be developed at the end of 2020 . The program aims to ensure the sustainability of the raw materials supply for the domestic timber industry. Acacia spp. (mangium /hybrid) and rubberwood (Timber Latex Clone) are the two major species out of nine selected species under this program.

A. mangium is one of the fast-growing and sustainable species for potentials timber production. It has a wood density ranging from $420 \mathrm{~kg} / \mathrm{m}^{3}$ to $483 \mathrm{~kg} / \mathrm{m}^{3}$ for green soaked volume and $500 \mathrm{~kg} / \mathrm{m}^{3}$ to $600 \mathrm{~kg} / \mathrm{m}^{3}$ in dry condition (Sarmin et al. 2014). In another study, the density of A. mangium was reported to fall within a range of $290 \mathrm{~kg} / \mathrm{m}^{3}$ to $675 \mathrm{~kg} / \mathrm{m}^{3}$. The density increases as the age of trees increased from 2 years to 20 years (Nordahlia et al. 2013). The density of wood is the best method to determine the quality of wood and correlated to its product's strength and shrinkage (Nugroho et al. 2012, Miranda et al. 2007, Lim et al. 2003). Wood is a renewable material and it has many applications. However, wood is easily degraded by sunlight, moisture and temperature due to the organic structure and the most important challenges of the components of wood are thermal decomposition of cellulose, lignin and hemicellulose at the low temperature $\left(100{ }^{\circ} \mathrm{C}\right.$ to $\left.150^{\circ} \mathrm{C}\right)$ (Aydemir et al. 2016). Hence, wood has different degradation points and is highly dependent on their specific chemical compositions.

The selection of the adhesives to manufacture the CLT is very important as it needs to meet the characteristics and the application of the CLT itself. Polyurethane (PUR) adhesive glue is well known as a formaldehyde-free adhesive for exterior grade structure application for GLULAM and finger-joint in several European countries (Richter et al. 2006). Other than that, the thermal properties of the CLT are also very important but there is very limited information on this topic been reported. According to Asim et al. (2018), excellent thermal and fire-retardant behaviour of phenol resorcinol formaldehyde (PRF) adhesive glue allowed it to be used in building structural materials and automobile industry. Some studies have been conducted to compare the performance of PRF and PUR adhesives in CLT fabrication. Norwahyuni et al. (2019a) compared both PRF and PUR adhesive in bonding CLT from A. mangium wood. The authors reported that PRF adhesive performed better than that of PUR adhesive as it led to higher shear bond strength and wood failure percentage. In another study, Norwahyuni et al. (2019b) evaluated the mechanical and physical properties of A. mangium CLT bonded with PRF and PUR. The results revealed that the CLT bonded with PRF adhesive exhibited higher mechanical properties compared to that of the PUR-bonded CLT. Nevertheless, information on the thermal stability of PRF and PUR in CLT manufacturing is rather limited.

Therefore, the objective of this study is to evaluate the thermal properties of neat PRF and PUR adhesive, A. mangium wood as well as the glue line formed between wood and adhesive. The glue line formed between two adjacent layers of wood is important as it might impart some thermal resistance to the wood itself. Through thermal studies, the thermal degradation, weight loss, final residue, decomposition temperature of each component samples was assessed based on peak DTG curves, storage modulus, loss modulus and damping factor 
of the samples.

\section{MATERIALS AND METHODS}

\section{Manufacturing Cross Laminated Timber (CLT) species}

Twenty-year-old $A$. mangium wood with a density of $673 \mathrm{~kg} / \mathrm{m}^{3}$ and moisture content of $12 \% \pm 3 \%$ was obtained from a local lumber mill located at Bukit Rambai, Melaka, Malaysia. The wood was sawn, trimmed and planed into $1000 \mathrm{~mm}$ long by $70 \mathrm{~mm}$ wide and $18,2 \mathrm{~mm}$ thick lumber. In this study, a 3-layer CLT of 1000 $\mathrm{mm} \times 280 \mathrm{~mm} \times 54,5 \mathrm{~mm}$ in size was produced by gluing three pieces of lumbers parallel and perpendicular to each other with edge bonding with $90^{\circ}$ alternating transverse CLT layers. Boards were glued using two types of adhesive, namely phenol resorcinol formaldehyde (PRF) and one component polyurethane (PUR). Both types of adhesives were applied to the samples at a spreading rate of $250 \mathrm{~g} / \mathrm{m}^{2}$ within a short time to avoid possible oxidation and dimensional instability. The assemblies were then subjected to a pressure of $1,5 \mathrm{~N} / \mathrm{mm}^{2}$ at $30{ }^{\circ} \mathrm{C}$ for 90 minutes using a compressive machine. In the next stage, the laminated panels were conditioned at 65 $\% \pm 5 \% \mathrm{RH}$ and $20^{\circ} \mathrm{C} \pm 2{ }^{\circ} \mathrm{C}$ for 2 weeks before cutting them into specimens for properties evaluation. Two types of adhesives were used in this study i.e., phenol resorcinol formaldehyde (PRF 1734 AkzoNobel) and one component polyurethane (1C-PUR or PUR, Jowapur 687,22). Hardener 2734 (commercial code) was also used in the preparation of PRF at a ratio of 100 to 25 parts by weight of PRF to hardener.

\section{Characterization of the samples}

\section{Thermogravimetric Analysis (TGA)}

Thermal stability of both PRF and PUR adhesives, A. mangium wood and glueline formed between wood and adhesives after pressing were characterized using Thermogravimetric analyzer (TGA Q 500 TA Instrument, USA) at Institute of Tropical Forestry and Forest Product (INTROP), University Putra Malaysia (UPM). In order to eliminate the effect of initial mass, $10 \mathrm{mg}$ of sample was used for each experiment and placed in an alumina crucible. Non-isothermal TGA was conducted with the temperature raised from $10{ }^{\circ} \mathrm{C}$ to $900{ }^{\circ} \mathrm{C}$ with a rate of $10^{\circ} \mathrm{C} / \mathrm{min}$ in an oxygen atmosphere. The gas was purged at a constant flow rate of $30 \mathrm{~mL} / \mathrm{min}$. Three replications were used for every adhesive type tested. A total of 15 specimens ( 3 x (PRF and PUR adhesives + A. mangium wood + glueline formed by both adhesives)) were tested in this study.

\section{Dynamic mechanical analysis (DMA)}

Dynamic mechanical analysis (DMA) was executed to determine the viscoelastic behaviour of specimens from $30^{\circ} \mathrm{C}$ to $150^{\circ} \mathrm{C}$ with a heating rate of $5{ }^{\circ} \mathrm{C} / \mathrm{min}$ and controlled sinusoidal strain. DMA test was performed by employing TA (DMA Q 800) instrument at INTROP, University Putra Malaysia, and operating in a threepoint bending mode with $1 \mathrm{~Hz}$ oscillation frequency under controlled amplitude. The specimens having dimensions of $60 \mathrm{~mm} \times 12 \mathrm{~mm} \times 6 \mathrm{~mm}(1 \times \mathrm{w} \times \mathrm{t})$ were used for the testing. For DMA, only PRF and PUR gluelines were tested with three replications each. Therefore, a total of 6 specimens were evaluated.

\section{RESULTS AND DISCUSSION}

\section{Thermogravimetric Analysis (TGA)}

Heat resistance of a material is one of the most important criteria in any building construction. Since wood is combustible, the application of wood as building material becomes very limited. Thus, thermal evaluation is an essential method to determine the capability of the material to resist heat. In general, TGA is used to observe the material's thermal stability and degradation behaviour. TGA analysis on the neat adhesive (PRF and PUR), glue line between wood and the adhesive and A. mangium wood are demonstrated in Figure 1 and Table 1. 


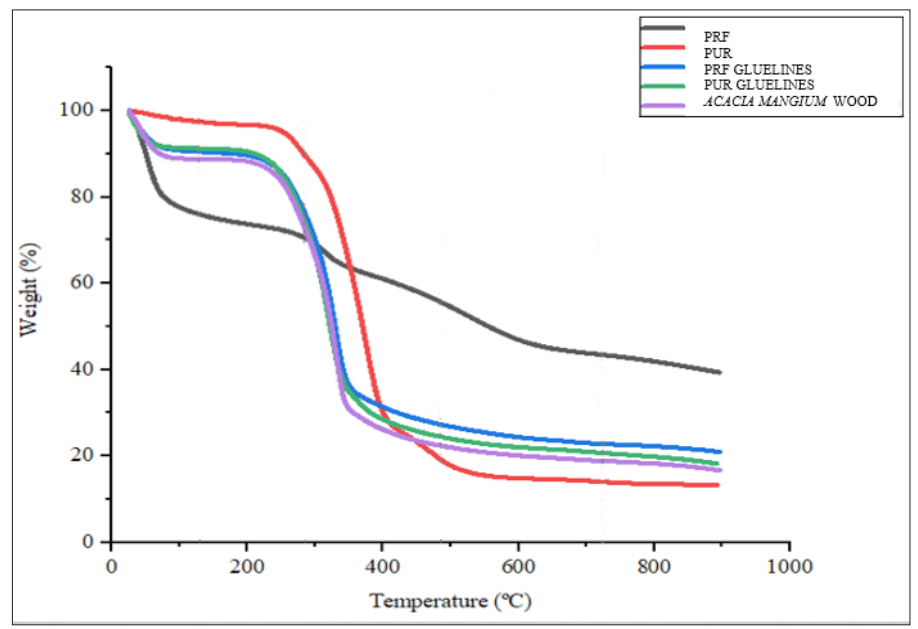

Figure 1: TGA curve of PRF, PUR, PRF glue line, PUR glue line and A. mangium wood.

During thermal degradation, drying of free water and major mass loss due to devolatilization and thermal debonding has been observed. All samples experienced a slight weight loss at temperature below $100{ }^{\circ} \mathrm{C}$ as shown in Figure 1 due to evaporation or dehydration of the water molecules (Sanyang et al. 2015, Nadirah et al. 2012, Johar et al. 2012). Significant weight loss $(26,8 \%)$ was observed for PRF adhesive glue at a temperature less than $100{ }^{\circ} \mathrm{C}$ due to the high amount of volatile free formaldehyde and phenol other than free water removal. This finding was aligned with the findings from previous studies done by Asim et al. (2018) and Liu et al. (2017). Both adhesives showed similar initial degradation temperature which occurred at $220^{\circ} \mathrm{C}$. However, PUR adhesive showed a higher weight loss of 74,40\% compared to PRF adhesive with the amount of weight loss of $47,92 \%$ during the main degradation process. This finding could be attributed to the availability of the thermally unstable urethane bond in PUR adhesive that leads to rapid degradation (Lee et al. 2002).

Table 1: Thermogravimetric analysis (TGA) results.

\begin{tabular}{|l|c|c|c|c|}
\hline Sample & $\begin{array}{c}\text { Initial degradation } \\
\text { temperature } \\
\left({ }^{\circ} \mathrm{C}\right)\end{array}$ & $\begin{array}{c}\text { Final degradation } \\
\text { temperature } \\
\left({ }^{\circ} \mathrm{C}\right)\end{array}$ & $\begin{array}{c}\text { Weight } \\
\text { loss } \\
(\%)\end{array}$ & $\begin{array}{c}\text { Final residue } \\
\text { at } 900{ }^{\circ} \mathrm{C} \\
(\%)\end{array}$ \\
\hline PRF adhesive & 220 & 530 & 47,92 & 39,37 \\
\hline PUR adhesive & 220 & 430 & 74,40 & 13,24 \\
\hline A. mangium wood & 140 & 380 & 72,38 & 16,72 \\
\hline PRF Glueline & 140 & 360 & 65,43 & 20,94 \\
\hline PUR Glueline & 130 & 420 & 72,57 & 18,26 \\
\hline
\end{tabular}

Meanwhile, the weight loss of the A. mangium wood sample starts to occur between $30{ }^{\circ} \mathrm{C}$ up to about 130 ${ }^{\circ} \mathrm{C}$, due to the hydrophilic nature of wood which resulted in high moisture absorption (Crespo et al. 2015, Angelini et al. 2009). The main degradation of $A$. mangium wood occurred at $140{ }^{\circ} \mathrm{C}$ up to $380{ }^{\circ} \mathrm{C}$ and this low thermal stability performance is attributed to the degradation of lignocellulosic components of the wood (hemicellulose, cellulose and lignin) (Manya et al. 2003). Higher lignocellulosic components caused a higher mass loss and lower initial degradation temperature (Lee et al. 2018, Lee et al. 2017). The first peak was attributed to the decomposition of hemicellulose, while the second peak can be attributed to the cellulose while degradation of lignin occurred at the wide temperature range and overlapping with the degradation of other components (Di Blasi 2008, Mészáros et al. 2004).

On the other hand, when both adhesives were applied to A. mangium wood (PRF glue line and PUR glue line), thermal degradation was expected to be similar to the degradation of pure A. mangium wood. This is because only 
a small portion of the specimen's mass was being replaced by higher thermal stability adhesive glue. Although the use of adhesive does not improve the specimen's degradation temperature, the glue application slightly reduces the mass loss. PRF glue line specimen was reported to have a better integrity structure at temperature range up to 900 ${ }^{\circ} \mathrm{C}$ with $20,94 \%$ of total residue compared to pure A. mangium wood and PUR glue line with the mass residue of $16,72 \%$ and $18,26 \%$, respectively. This result could be attributed to good bonding properties between PRF adhesive and A. mangium wood compared to PUR adhesive.

Derivative thermo-gravimetric (DTG) analysis of both PRF and PUR adhesives, A. mangium wood and glueline of both PRF and PUR are shown in Figure 2. DTG analysis is used to study the rate of degradation of the materials up to a certain temperature (Ridzuan et al. 2016). Three peaks were observed for all specimens which are below $100{ }^{\circ} \mathrm{C}, 280{ }^{\circ} \mathrm{C}$ to $380^{\circ} \mathrm{C}$ and $420^{\circ} \mathrm{C}$ to $520^{\circ} \mathrm{C}$. A low first degradation peak responsible for free water removal except for PRF adhesive glue. A maximum decomposition rate at 4,83\%/min for PRF was observed due to the presence of hydroxyl molecule in PRF adhesive glue (Asim et al. 2016). All specimens demonstrate the maximum rate of weight losses in the second peak except PRF adhesive glue. A. mangium wood showed a higher DTG value at the second peak among all the samples. Meanwhile, the application of adhesive glues (PRF and PUR) on A. mangium wood seems to reduce the rate of weight loss as part of the specimen's mass replaced by higher thermal stability materials. No significant changes showed at the third region of DTG peaks for all samples.

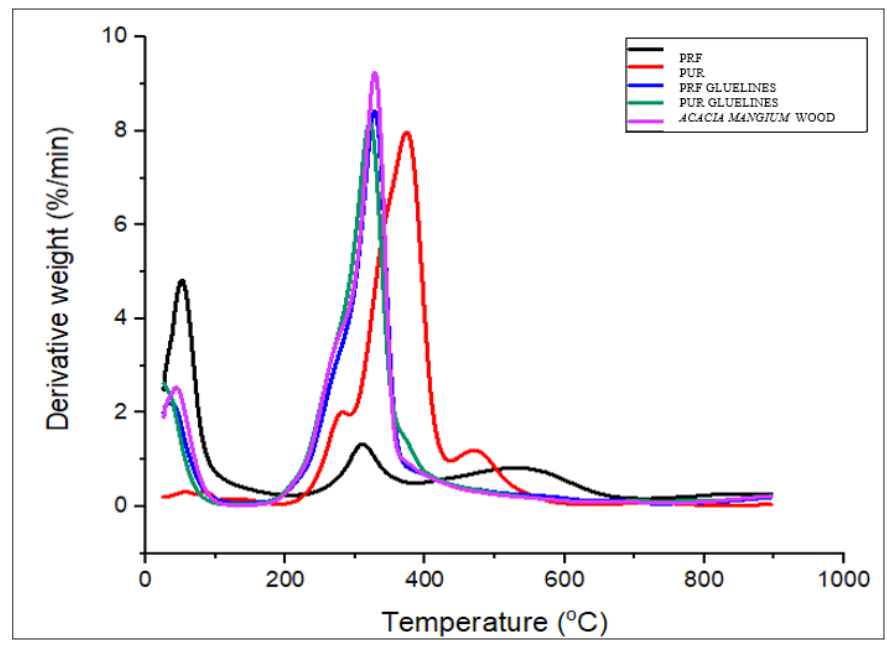

Figure 2: DTG curve of PRF, PUR, PRF glueline, PUR glueline and A. mangium wood.

\section{Dynamic mechanical analysis (DMA)}

DMA is one of the most functional analysis to investigate the morphological and viscoelastic properties of a material. It helps to analyse some other parameters such as primary relaxations, storage or loss compliance, dynamic fragility, cross-linking density, creep compliance and dynamic viscosity (Ornaghi et al. 2012, Pistor et al. 2012, Joseph et al. 2010, Qazvini and Mohammadi 2005). It is a technique where small deformation is applied in a cyclic manner.

In this section, only the glue lines formed by PRF and PUR adhesives were tested and discussed. Figure 3 illustrates the storage modulus of PRF and PUR adhesive glue lines of CLT made by A. mangium wood. According to Saba et al. (2016a), there are three regions found for viscoelastic materials, namely glassy region, transition region and rubbery region. High storage modulus value indicated the glassy region where the components are in tightly packed and drop as it reached the glass transition temperature $\left(T_{\mathrm{g}}\right)$. This is because slipping of polymer chain above $\mathrm{T}_{\mathrm{g}}$ reduces its modulus and performances. As the temperature increase, the component tends to increase in mobility correspond to rubbery state transition (Jawaid and Khalil 2011, Hameed et al. 2007, Jacob et al. 2006). The investigation of various storage modulus with a temperature of CLT was found to decrease with temperature increment. At low temperature, the storage modulus PRF glue line is higher but close to PUR glue line, suggesting that PRF glue line has better stiffness but lower mobility and flexibility (Chartoff et al. 2009). This finding was synchronized with 
TGA results reported in the above section where PRF glue line has better interfacial bonding between wood and PRF glue. Besides, a sudden drop in storage modulus at about $100^{\circ} \mathrm{C}$ for both glue lines represents glass transition temperature, $\mathrm{T}_{\mathrm{g}}$ zone.

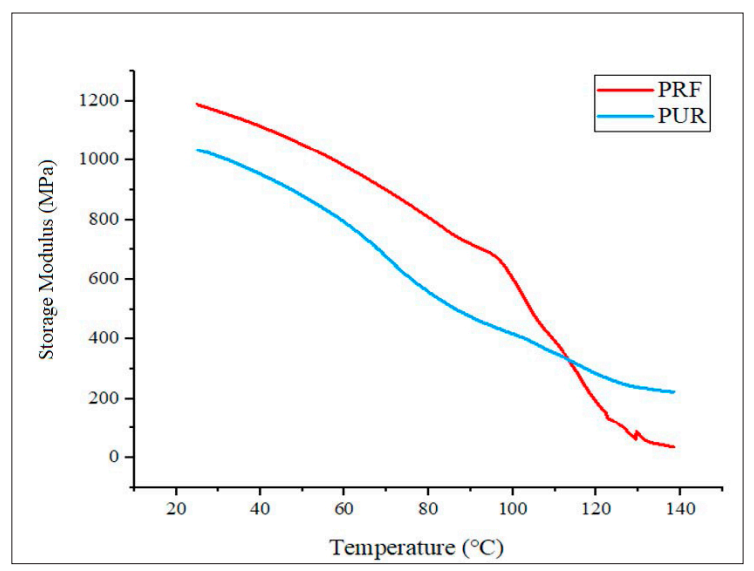

Figure 3: Storage Modulus of PRF glueline and PUR glueline.

Meanwhile, the loss modulus measurement is carried out on the energy dissipation response under the reciprocate deformation of a material (Jawaid et al. 2012). The loss modulus of PRF and PUR adhesive glue line of CLT made by $A$. mangium wood are illustrated in Figure 4. Both curves at maximum value indicates maximum dissipation of mechanical energy at lower temperature and decreased dramatically at higher temperature due to the free movement of polymer (Saba et al. 2016b). From Figure 4, both glue lines demonstrated a wide peak at $60{ }^{\circ} \mathrm{C}$ to 100 ${ }^{\circ} \mathrm{C}$ and the $\mathrm{T}_{\mathrm{g}}$ observed for PRF glue line is slightly lower than PUR glue line. This is because the inter-molecular friction in the PRF glue line was higher and increases the dissipation of energy within CLT (Hameed et al. 2007). PRF glue line resulted in a higher loss of modulus due to the increased amount of energy needed to disentangle a better interfacial bonding.

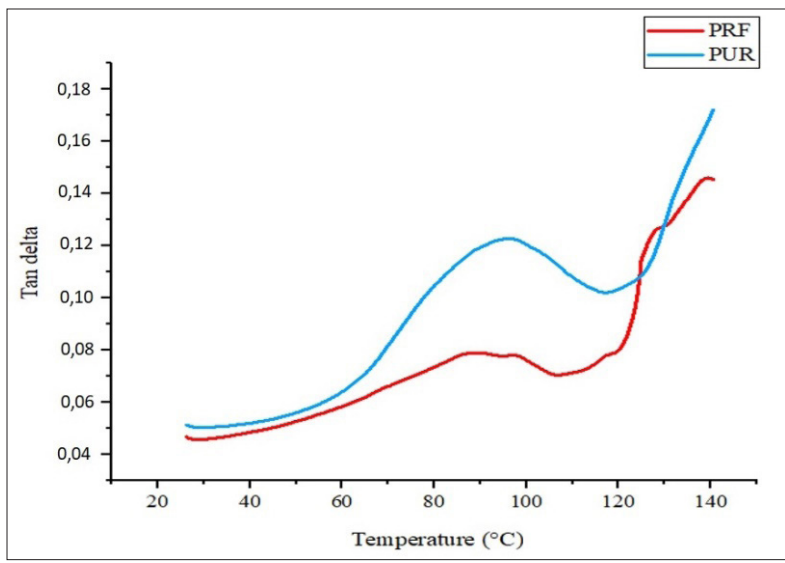

Figure 4: Loss Modulus of PRF glueline and PUR glueline.

Damping factor determines the ability of material on absorbing energy at a range of temperature or frequency. Damping is important when designing advanced structural especially when vibration and noise control involved. Besides, it is used to study the fatigue life and impact resistance of structural materials and monitor damage (Melo and Radford 2005). Figure 5 depicts the damping factor curve trend of the CLT for both types of glue lines with the temperature at frequency of $1 \mathrm{~Hz}$. At temperature below $\mathrm{T}_{\mathrm{g}}$, low $\tan \delta$ corresponds to close pack molecular structure. Whilst the temperature sweep, the tan $\delta$ increased indicate both glue lines become more viscous. A wide area of $\tan \delta$ peak for PUR glue line observed in this test reflecting higher dynamic fragility, due to poor interfacial bonding between adhesive and wood. On the other hand, the lower tan $\delta$ peak of PRF glue line showed a good in- 
terfacial adhesion similar to the results of storage modulus (Jawaid and Khalil 2011). From the $\tan \delta$ curve in Figure $5, \mathrm{~T}_{\mathrm{g}}$ of PRF glue line was also observed to be slightly lower than PUR glue line. George et al. (2003) evaluated two commercial PRF and PUR adhesives using thermomechanical analysis (TMA) and found that wood joints bonded with PUR exhibited a significant temperature-dependant creep. The finding suggested that PUR is not suitable for structural application. As in this study, similar conclusion can be drawn, where PUR is an inferior adhesive compared to PRF in the manufacturing of CLT.

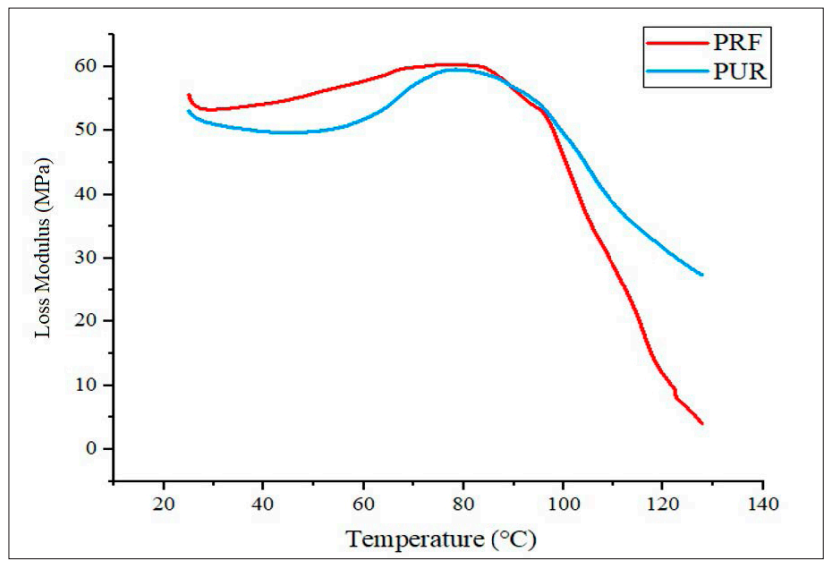

Figure 5: Damping Factor of PRF glue line and PUR glue line.

\section{CONCLUSIONS}

In this study, thermogravimetric analysis was performed on both neat PRF and PUR adhesives, A. mangium wood, as well as glue lines of both PRF and PUR, formed after CLT fabrication process. On the other hand, dynamic mechanical analysis was conducted to characterize the PRF and PUR glue lines. Generally, it was found that PRF adhesive glue was more thermally stable than PUR adhesive glue, with a higher percentage of residue in TGA test. Both adhesive glues start the degradation at the same temperature of $220{ }^{\circ} \mathrm{C}$ but PRF adhesive showed higher degradation temperature at $530{ }^{\circ} \mathrm{C}$ at the second stage with a lower percentage of weight loss of $47,92 \%$. As expected, $A$. mangium wood specimen has the lowest thermal properties due to the low thermal stability of hemicellulose. The application of adhesives glue on A. mangium did improve the thermal stability of the wood by reducing weight loss during the degradation process. In comparison, PRF glue line has better thermal stability compared to that PUR glue line as indicated by its higher residue at temperature up to $900{ }^{\circ} \mathrm{C}$.

In DMA, the storage modulus of PRF glue line is higher but close to PUR glue line, suggesting that PRF glue line has better stiffness but lower mobility and flexibility. A sudden drop in storage modulus at about 100 ${ }^{\circ} \mathrm{C}$ for both glue lines, indicating glass transition temperature, $\mathrm{T}_{\mathrm{g}}$ and major main chain slipping were found. The $\mathrm{T}_{\mathrm{o}}$ of PRF glue line observed from $\tan \delta$ and loss modulus curve was slightly lower than that of PUR glue line. Besides, PRF glue line resulted in a higher loss of modulus due the increased amount of energy needed to disentangle a better interfacial bonding. A similar trend was also found in loss modulus and $\tan \delta$ curves. Based on results obtained, it can be concluded that PRF adhesive is a better binding agent for A. mangium wood in the manufacturing of CLT as it resulted in better interfacial bonding and a promising thermal performance at higher working temperature compared to PUR.

\section{ACKNOWLEDGEMENTS}

This study was financially supported by the Higher Institution Centre of Excellence (HiCoE) for the project titled "Development of aeronautic composites made from biophenolic microspheres from plant sourced" (Code: 6369109) granted to Paridah Md Tahir. The authors also would like to extend their gratitude for the facilities support from HLM Wood Products Sdn. Bhd. 


\section{REFERENCES}

Angelini, L.G.; Ceccarini, L.; Nassi O Di Nasso, N.; Bonari, E. 2009. Comparison of Arundo Donax L. and Miscanthus x Giganteus in a long-term field experiment in central Italy: analysis of productive characteristics and energy balance. Biomass Bioenerg 33(4): 635-643. https://doi.org/10.1016/j.biombioe.2008.10.005

Asim, M.; Jawaid, M.; Abdan, K.; Ishak, M.R. 2016. Effect of alkali and silane treatments on mechanical and fibre-matrix bond strength of kenaf and pineapple leaf fibres. J Bionic Eng 13(3): 426-435. https://doi.org/10.1016/S1672-6529(16)60315-3

Asim, M.; Jawaid, M.; Nasir, M.; Saba, N. 2018. Effect of fiber loadings and treatment on dynamic mechanical, thermal and flammability properties of pineapple leaf fiber and kenaf phenolic composites. $J$ Renew Mater 6(4): 383-393. https://doi.org/10.7569/JRM.2017.634162

Aydemir, D.; Civi, B.; Alsan, M.; Can, A.; Sivrikaya, H.; Gunduz, G.; Wang, A. 2016. Mechanical, morphological and thermal properties of nano-boron nitride treated wood materials. Maderas-Cienc Tecnol 18(1): 19-32. http://dx.doi.org/10.4067/S0718-221X2016005000003

Crespo, Y.A.; Naranjo, R.A.; Burgos, J.C.V.; Sanchez, C.G.; Sanchez, E.M. 2015. Thermogravimetric analysis of thermal and kinetic behavior of Acacia mangium wood. Wood Fiber Sci 47(4): 327-335. http://wfs.swst.org/index.php/wfs/article/view/2363

Chartoff, R.P.; Menczel, J.D.; Dillman, S.H. 2009. Dynamic Mechanical Analysis (DMA). In Thermal Analysis of Polymers: Fundamentals and Applications, Menzcel, J.D.; Bruce Prime, R. (Eds.). John Wiley and Sons: New Jersey, USA. pp. 387-495. https://doi.org/10.1002/9780470423837.ch5

Di Blasi, C. 2008. Modeling chemical and physical processes of wood and biomass pyrolysis. Prog Energy Combust Sci 34(1): 47-90. http://doi.org/10.1016/j.pecs.2006.12.001

Dieste, A.; Cabrera, M.N.; Clavijo, L.; Cassell, N. 2019. Analysis of wood products from an added value perspective: the Uruguayan forestry case. Maderas-Cienc Tecnol 21(3): 305 - 316. http://dx.doi.org/10.4067/S0718-221X2019005000303

Engineering Toolbox. 2004. Density of various wood species. https://www.engineeringtoolbox.com/ wood-density-d_40.html

George, B.; Simon, C.; Properzi, M.; Pizzi, A.; Elbez, G. 2003. Comparative creep characteristics of structural glulam wood adhesives. Holz Roh Werkst 61(1): 79-80. https://doi.org/10.1007/s00107-002-0348-3

Hameed, N.; Sreekumar, P.A.; Francis, B.; Yang, W.; Thomas, S. 2007. Morphology, dynamic mechanical and thermal studies on poly (styrene-co-acrylonitrile) modified epoxy resin/glass fibre composites. Compos Part A Appl Sci Manuf 38(12): 2422-2432. https://doi.org/10.1016/j.compositesa.2007.08.009

Jacob, M.; Francis, B.; Varughese, K.; Thomas, S. 2006. The effect of silane coupling agents on the viscoelastic properties of rubber biocomposites. Macromol Mater Eng 291(9): 1119-1126. https://doi.org/10.1002/mame.200600171

Jawaid, M.; Abdul Khalil, H.P.S.; Alattas, O. 2012. Woven hybrid biocomposites: dynamic mechanical and thermal properties. Compos Part A Appl Sci Manuf 43(2): 288-293. https://doi.org/10.1016/j.compositesa.2011.11.001

Jawaid, M.; Abdul Khalil, H.P.S. 2011. Effect of layering pattern on the dynamic mechanical properties and thermal degradation of oil palm-jute fibers reinforced epoxy hybrid composite. BioResources 6(3): 23092322. https://ojs.cnr.ncsu.edu/index.php/BioRes/article/view/BioRes_06_3_2309_Jawaid_A_Layering_Pattern_DMA_Epoxy_Hybrid_Composites 
Johar, N.; Ahmad, I.; Dufresne, A. 2012. Extraction, preparation and characterization of cellulose fibres and nanocrystals from rice husk. Ind Crops Prod 37(1): 93-99. https://doi.org/10.1016/j.indcrop.2011.12.016

Joseph, S.; Appukuttan, S.P.; Kenny, J.M.; Puglia, D.; Thomas, S.; Joseph, K. 2010. Dynamic Mechanical Properties of oil palm microfibril-reinforced natural rubber composites. J Appl Polym Sci 117(3): 1298-1308. https://doi.org/10.1002/app.30960

Lee, C.H.; Sapuan, S.M.; Hassan, M.R. 2018. Thermal analysis of kenaf fiber reinforced floreon biocomposites with magnesium hydroxide flame retardant filler. Polym Compos 39(3): 869-875. https://doi.org/10.1002/pc. 24010

Lee, C.H.; Sapuan, S.M.; Hassan, M.R. 2017. Mechanical and thermal properties of kenaf fiber reinforced polypropylene/magnesium hydroxide composites. J Eng Fiber Fabr 12(2): 50-58. https://doi.org/ 10.1177/155892501701200206

Lee, S.H.; Teramoto, Y.; Shiraishi, N. 2002. Biodegradable polyurethane foam from liquefied waste paper and its thermal stability, biodegradability, and genotoxicity. J Appl Polym Sci 83(7): 1482-1489. https://doi.org/10.1002/app.10039

Lim, S.C.; Gan, K.S.; Choo, K.T. 2003. The characteristics, properties and uses of plantation timbers; rubberwood and Acacia mangium. Timber Technology Bulletin 26: 1-10. https://info.frim.gov.my/infocenter/booksonline/ttb/TTBno26.pdf

Liu, J.; Chen, R.Q.; Xu, Y.Z.; Wang, C.P.; Chu, F.X. 2017. Resorcinol in high solid phenol-formaldehyde resins for foams production. J Appl Polym Sci 134(22): 44881. https://doi.org/10.1002/app.44881

Manya, J.J.; Velo, E.; Puigjaner, L. 2003. Kinetics of biomass pyrolysis: a reformulated three-parallel-reactions model. Ind Eng Chem Res 42(3): 434-441. https://doi.org/10.1021/ie020218p

Melo, J.D.; Radford, D.W. 2005. Time and temperature dependence of the viscoelastic properties of cfrp by dynamic mechanical analysis. Compos Struct 70(2): 240-253. https://doi.org/10.1016/j.compstruct.2004.08.025

Mészáros, E.; Várhegyi, G.; Jakab, E.; Marosvölgyi, B. 2004. Thermogravimetric and reaction kinetic analysis of biomass samples from an energy plantation. Energ Fuel 18(2): 497-507. https://doi.org/10.1021/ef034030

Miranda, I.M.; Almeida, H.; Pereira, H. 2007. Influence of provenance, subspecies, and site on wood density in Eucalyptus globulus Labill. Wood Fiber Sci 33(1): 9-15. https://wfs.swst.org/index.php/wfs/article/ view/66

Nadirah, W.O.; Jawaid, M.; Al Masri, A.A.; Abdul Khalil, H.P.S.; Suhaily, S.S.; Mohamed, A.R. 2012. Cell wall morphology, chemical and thermal analysis of cultivated pineapple leaf fibres for industrial applications. J Polym Environ 20(2): 404-411. https://doi.org/10.1007/s10924-011-0380-7

Nordahlia, A.S.; Hamdan, H.; Anwar, U.M.K. 2013. Wood properties of selected plantation species: Khaya ivorensis (african mahogany), Azadirachta excelsa (sentang), Endospermum malaccense (sesendok) and Acacia mangium. Timber Technology Bulletin 51: 1-4. https://info.frim.gov.my/infocenter/booksonline/ ttb/TTB51.pdf

Norwahyuni, M.Y.; Tahir, P.M.; Roseley, A.S.M.; Lee, S.H.; Halip, J.A.; James, R.M.S.; Ashaari, Z. 2019a. Bond integrity of cross laminated timber from Acacia mangium wood as affected by adhesive types, pressing pressures and loading direction. Int $J$ Adhes Adhes 94: 24-28. https://doi.org/10.1016/j.ijadhadh.2019.05.010

Norwahyuni, M.Y.; Tahir, P.M.; Lee, S.H.; Khan, M.A.; James, R.M.S. 2019b. Mechanical and physical properties of Cross-Laminated Timber made from Acacia mangium wood as function of adhesive types. $J$ Wood Sci 65(1): 20. https://doi.org/10.1186/s10086-019-1799-z

Nugroho, W.D.; Marsoem, S.N.; Yasue, K.; Fujiwara, T.; Nakajima, T.; Hayakawa, M.; Nakaba, S.; Yamagishi, Y.; Jin, H.; Kubo, T.; Funada, R. 2012. Radial variations in the anatomical characteristics and 
density of the wood of Acacia mangium of five different provenances in Indonesia. $J$ Wood Sci 58(3): 185-194. https://doi.org/10.1007/s10086-011-1236-4

Ornaghi, H.L.; Pistor, V.; Zattera, A.J. 2012. Effect of the epoxycyclohexyl polyhedral oligomeric silsesquioxane content on the dynamic fragility of an epoxy resin. J Non Cryst Solids 358(2): 427-432. https://doi.org/10.1016/j.jnoncrysol.2011.10.014

Pistor, V.; Ornaghi, F.G.; Ornaghi, H.L.; Zattera, A.J. 2012. Dynamic mechanical characterization of epoxy/epoxycyclohexyl-POSS nanocomposites. J Mater Sci Eng A 532: 339-345. https://doi.org/10.1016/j.msea.2011.10.100

Qazvini, N.T.; Mohammadi, N. 2005. Dynamic Mechanical Analysis of segmental relaxation in unsaturated polyester resin networks: effect of styrene content. Polymer 46(21): 9088-9096. https://doi.org/10.1016/j.polymer.2005.06.118

Ridzuan, M.J.M.; Majid, M.A.; Afendi, M.; Mazlee, M.N.; Gibson, A.G. 2016. Thermal behaviour and dynamic mechanical analysis of pennisetum purpureum/glass-reinforced epoxy hybrid composites. Compos Struct 152: 850-859. https://doi.org/10.1016/j.compstruct.2016.06.026

Richter, K.; Pizzi, A.; Despres, A. 2006. Thermal stability of structural one-component polyurethane adhesives for wood-structure-property relationship. $J$ Appl Sci 102(6): 5698-5707. https://doi.org/10.1002/app.25084

Saba, N.; Jawaid, M.; Alothman, O.Y.; Paridah, M. T. 2016a. A review on dynamic mechanical properties of natural fibre reinforced polymer composites. Constr Builds Mater 106(1): 149-159. https://doi.org/10.1016/j.conbuildmat.2015.12.075

Saba, N.; Paridah, M.T.; Abdan, K.; Ibrahim, N.A. 2016b. Dynamic Mechanical Properties of oil palm nano filler/kenaf/epoxy hybrid nanocomposites. Constr Builds Mater 124: 133-138. https://doi.org/10.1016/j.conbuildmat.2016.07.059

Sarmin, S. N.; Rosman, N.; Kasim, J.; Zakaria, S. A. K. Y. 2014. Effects of Different Resin Content and Densities on Some Properties of Hybrid Wood Sawdust-Acacia mangium Composites. In Proceedings of the International Conference on Science, Technology and Social Sciences (ICSTSS) 2012. pp. 485-491. Springer: Singapore. https://doi.org/10.1007/978-981-287-077-3_57

Sanyang, M.L.; Sapuan, S.M.; Jawaid, M.; Ishak, M.R.; Sahari, J. 2015. Effect of plasticizer type and concentration on tensile, thermal and barrier properties of biodegradable films based on sugar palm (Arenga pinnata) starch. Polymer 7(6): 1106-1124. https://doi.org/10.3390/polym7061106

Shukla, S.R. 2019. Evaluation of dimensional stability, surface roughness, colour, flexural properties and decay resistance of thermally modified Acacia auriculiformis. Maderas-Cienc Tecnol 21(4): 433-446. http://dx.doi.org/10.4067/S0718-221X2019005000401

Sutton, A.; Black, D.; Walker, P. 2011. Cross-Laminated Timber: an introduction to low-impact building materials. IHS BRE Press: Watford, UK.

Van De Kuilen, J.W.G.; Ceccotti, A.; Xia, Z.; He, M. 2011. Very tall wooden buildings with cross laminated timber selection and/or peer-review under responsibility. Procedia Eng 14: 1621-1628. https://doi.org/10.1016/j.proeng.2011.07.204

Wang, Z.; Zhou, J.; Dong, W.; Yao, Y.; Gong, M. 2018. Influence of technical characteristics on the rolling shear properties of cross laminated timber by modified planar shear tests. Maderas-Cienc Tecnol 20(3): 469-478. http://dx.doi.org/10.4067/S0718-221X2018005031601 